Syntax Literate : Jurnal Ilmiah Indonesia p-ISSN: 2541-0849

e-ISSN : 2548-1398

Vol. 5, No.4 April 2020

\title{
PENDAMPINGAN PROGRAM PENGHIJAUAN DAERAH RESAPAN BENDUNGAN SETU PATOK KABUPATEN CIREBON
}

\section{Nurdiyanto, Akbar Winasis dan Heri Mulyono}

Universitas Swadaya Gunung Jati Cirebon

Email: nurdiantomjl@gmail.com, akbarwinasis909@gmail.com dan

mulyonoh29@gmail.com

\section{Abstract}

The lecturer service activities are carried out in Setu Patok Village, Mundu District, Cirebon Regency. The purpose of this activity is to increase public awareness of the importance of the environment, protect the environment from drought and maintain the water content of catchment areas through reforestation. The agenda in community service activities are: Socialization, Plant Seed Planting, Monitoring and Evaluation, Reporting and Publication. The socialization activity was carried out on January 23, 2020 in the hall of Setu Patok Village, Mundu District, Cirebon Regency. In this socialization activity, it was explained about the benefits of greening catchment areas around the Setu Patok Dam. The number of participants who attended was 23 people. Planted seedlings are types of fruit trees, with 21 trees. Monitoring activities carried out 5 days after planting trees. The indicators of the results of monitoring and evaluation are: Socialization is carried out properly, the community and stakeholders follow and respond to the activities and understanding of the material about greening catchment areas, living plants and growing in the planting location.

Keywords: Community Service, Socialization, Greening, Infiltration Areas

\section{Abstrak}

Kegiatan pengabdian dosen dilaksanakan di Desa Setu Patok Kecamatan Mundu Kabupaten Cirebon. Tujuan dari kegiatan ini adalah Meningkatkan kesadaran masyarakat akan pentingnya lingkungan, menjaga lingkungan dari bencana kekeringan dan menjaga kandungan air daerah resapan melalui penghijauan. Adapun agenda dalam kegiatan pengabdian pada masyarakat adalah: Sosialisasi, Penanaman Bibit Tanaman, Monitoring dan Evaluasi, Pelaporan dan Publikasi. Kegiatan sosialisasi dilaksanakan pada tanggal 23 Januari 2020 di aula Desa Setu Patok Kecamatan Mundu Kabupaten Cirebon. Dalam kegiatan sosialisasi ini dijelaskan tentang manfaat dari penghijauan daerah resapan di sekitar Bendungan Setu Patok. Adapun jumlah peserta yang hadir adalah 23 orang. Bibit tanaman yang ditanam adalah jenis tanaman buah-buahan, dengan jumlah pohon sebanyak 21 buah. Kegiatan monitoring dilakukan 5 hari setelah dilakukan penanaman pohon. Adapun indikator hasil monitoring dan Evaluasi adalah : Sosialisasi dilaksanakan dengan baik, Masyarakat dan stakeholders mengikuti dan merespon kegiatan serta pemahaman materi tentang penghijauan daerah resapan, tanaman hidup dan tumbuh di lokasi penanaman. 
Kata kunci: Pengabdian Masyarakat, Sosialisasi, Penghijauan, Daerah Resapan

\section{Pendahuluan}

Lingkungan selalu mengitari manusia dari waktu dilahirkan sampai meninggalnya, sehingga antara lingkungan dan manusia terdapat hubungan timbal balik dalam artian lingkungan mempengaruhi manusiadan manusia mempengaruhi lingkungan. Begitu pula dalam proses belajar mengajar, lingkungan merupakan sumber belajar yang banyak berpengaruh dalam proses belajar maupun perkembangan anak (Muslih, 2016).

Debit air Bendungan Setu Patok di Desa Setu Patok Kecamatan Mundu Kabupaten Cirebon terus menyusut. Kondisi ini menyusul kemarau berkepanjangan di kawasan pantura Cirebon. Salah satu upaya untuk mengatasi kekeringan akibat kemarau adalah penghijauan. Tanaman yang ditanam pada lahan-lahan kosong di sekitaran waduk mampu menjaga butiran tanah ketika hujan tiba. Tanaman yang rapat juga berfungsi untuk meningkatkan kemampuan tanah dalam menyerap air hujan, mengurangi aliran permukaan dan penguapan sehingga akhirnya air tanah akan tersedia lebih lama. Tanaman untuk penghijauan dipilih yang mampu menyerap dan menyimpan air seperti tanaman buah-buahan. Pada saat ini, yang paling sulit adalah melestarikan tanaman di sekitar waduk. Tanaman yang telah ada di sekitar waduk perlu terpelihara dengan baik. Oleh karena itu perlu diadakan "Pendampingan Program Penghijauan Daerah Resapan Bendungan Setu Patok Kabupaten Cirebon”. Dengan kegiatan pengabdian kepada masyarakat sekitar Desa Setu Patok Kecamatan Mundu Kabupaten Cirebon diharapkan dapat: Meningkatkan kesadaran masyarakat akan pentingnya lingkungan, Menjaga lingkungan dari bencana kekeringan dan Menjaga kandungan air melalui penghijauan daerah resapan.

Penghijauan daerah resapan di Indonesia diarahkan pada tiga prinsip utama yaitu perlindungan permukaan terhadap air hujan, meningkatkan kapasitas infiltrasi seperti pemberian bahan organik atau penyiapan keadaan yang diperlukan untuk pembenahan tata guna lahan dan perubahan pandangan dan gaya penduduk DAS hulu (Notohadiprawiro, Soekodarmodjo, \& Sukana, 2006). Meningkatnya kemampuan tanah dalam meresapkan air akan memperkecil peluang terjadinya aliran air di permukaan tanah atau banjir (Sebastian, 2008). Hal ini akan mengurangi bahaya banjir yang mungkin terjadi. Konservasi air pada prinsipnya adalah penggunaan air hujan yang jatuh ke tanah seefisien mungkin, dan mengatur waktu aliran agar tidak terjadi banjir yang dapat merusak serta tersedianya air pada musim kemarau. Usaha konservasi air bertujuan untuk:

1. Menjamin ketersediaan untuk generasi masa depan, pengurangan air dari sebuah ekosistem tidak akan melewati nilai penggantian alamiahnya.

2. Penghematan energi, pemompaan air, pengiriman, dan fasilitas pengolahan air limbah mengkonsumsi energi besar. 
3. Konservasi habitat, penggunaan air oleh manusia yang diminimalisir untuk membantu mengamankan simpanan sumber air untuk habitat liar lokal dan penerimaan migrasi aliran air, termasuk usaha-usaha baru pembangunan waduk dan infrastruktur berbasis air lainnya (Kutarga, Nasution, \& Tarigan, 2008).

Metode konservasi pada suatu DAS dilakukan melalui penghijauan, dilakukan untuk mengurangi erosi tebing sungai yang disebabkan oleh adanya kerusan aliran sungai yang terjadi pada saat hujan lebat dan secara tiba-tiba, ditambah lagi rusaknya hutan dan DAS di bahagian hulu (Suryani, Arifin, \& Hatta, 2017). Aliran air secara alami akan berada dalam kondisi terhambat hingga tergenang apabila dalam kondisi jenuh. Hal ini memerlukan penanganan yang tepat sehingga aliran tersebut dapat diperbaiki untuk mencapai muka air tanah. Daerah resapan mampu meningkatkan daya resap air hujan ke dalam tanah. Hal ini akan bermanfaat untuk mencegah genangan air yang mengakibatkan banjir, peningkatan cadangan air bersih di dalam tanah, dan mencegah erosi dan longsor. Dalam rangka mewujudkan pengelolaan sumber daya air secara terpadu ada tiga kriteria utama yang dijadikan acuan, yaitu:

\section{Efisiensi ekonomi}

Dengan meningkatnya kelangkaan air dan dengan sifat sumber daya air yang tersedia secara terbatas dan mudah tercemar, serta semakin meningkatnya permintaan maka efisiensi ekonomi penggunaan air sudah harus menjadi perhatian.

2. Keadilan

Air adalah salah satu kebutuhan dasar kehidupan, oleh sebab itu semua orang perlu mempunyai akses terhadap air yang mencukupi baik secara kuantitas maupun kualitas untuk mempertahankan kehidupannya.

3. Keberlanjutan lingkungan dan ekologi

Penggunaan sumber daya air haruslah dilakukan sedemikian rupa sehingga tidak mengorbankan kepentingan generasi yang akan datang terhadap air.

Ketiga kriteria tersebut perlu mendapat perhatian secara berimbang dari stakeholder dan penentu kebijakan (Semu, Arsyad, \& Umar, 2018). Dalam kaitan ini maka ada beberapa elemen penting dan pendekatan, yaitu :

1. Lingkungan yang memungkinkan (enabling environment) dalam bentuk kebijakan nasional, peraturan perundang-undangan, dan informasi tentang stakeholder pengelolaan sumber daya air

2. Peran kelembagaan (institusional roles) pemerintah dan stakeholders pada berbagai tingkatan

3. Instrumen-instrumen pengelolaan (managemen instruments) untuk pengaturan yang efektif (seperti regulasi pada berbagai tingkatan dari pusat sampai daerah), untuk monitoring, dan untuk penegakan aturan yang memungkinkan pengambil keputusan untuk membuat pilihan diantara alternatif pilihan yang tersedia.

Salah satu pengelolaan sumber daya air adalah dilaksanakan dalam rangka konservasi sumber daya air. Konservasi sumber daya air adalah upaya memelihara keberadaan serta keberlanjutan keadaan, sifat dan fungsi sumber daya air agar senantiasa tersedia dalam kuantitas dan kualitas yang memadai untuk memenuhi 
kebutuhan mahluk hidup, baik pada waktu sekarang maupun yang akan datang. Modernisasi yang terus berkembang ditandai dengan pesatnya pembangunan. Pepohonan buah sebagai penghasil oksigen dibutuhkan untuk respirasi manusia dan menjadi titik pusat perhatian di ruang terbuka hijau, ornamen buah yang berwarna menjadi perhatian masyarakat dan memilih untuk berteduh dibawahnya (Atmojo, Irwan, \& Rogomulyo, n.d.). Oleh karena itu suplay oksigen yang cukup dibutuhkan untuk generasi mendatang dapat dilakukan dengan menanam pohon di daerah resapan secara berkelanjutan dengan melaksanakan penghijauan. Penghijauan di Bendungan Setu Patok termasuk kedalam penghijauan publik (Suryani et al., 2017) karena dilaksanakan di tempat umum.

\section{Metode Penelitian}

Penelitian ini termasuk penelitian deskriptif (deskriptif research), yaitu penelitian yang bertujuan untuk menggambarkan sifat sesuatu yang tengah berlangsung pada saat riset dilakukan dan memeriksa sebab-sebab dari suatu gejala tertentu. Teknik pengambilan data dengan menggunakan metode Observasi, melakukan pengamatan langsung untuk memperoleh setiap aktivitas, melaksanakan sosialisasi dengan cara pendampingan di masyarakat dan melaksanakan penghijauan di daerah resapan. Teknik ini menuntut adanya pengamatan dari peneliti baik secara langsung ataupun tidak langsung terhadap objek penelitian.

\section{Hasil dan Pembahasan}

Kegiatan sosialisasi dilaksanakan pada tanggal 23 Januari 2020 di aula Desa Setu Patok Kecamatan Mundu Kabupaten Cirebon. Dalam kegiatan sosialisasi ini dijelaskan tentang manfaat dari penanaman pohon untuk penghijauan daerah resapan sekitar Setu Patok. Adapun jumlah peserta yang hadir adalah 23 orang. Setelah sosialisasi, kemudian dilakukan tanya jawab dan diskusi dengan stakeholder wilayah setempat.

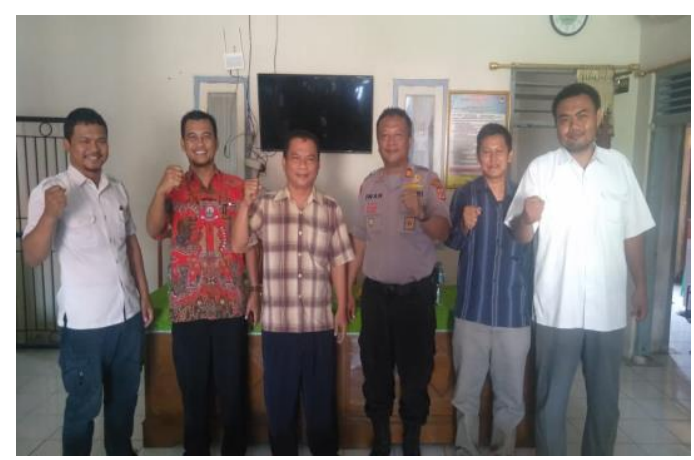

Gambar 1.

Sosialisasi dengan pihak desa 


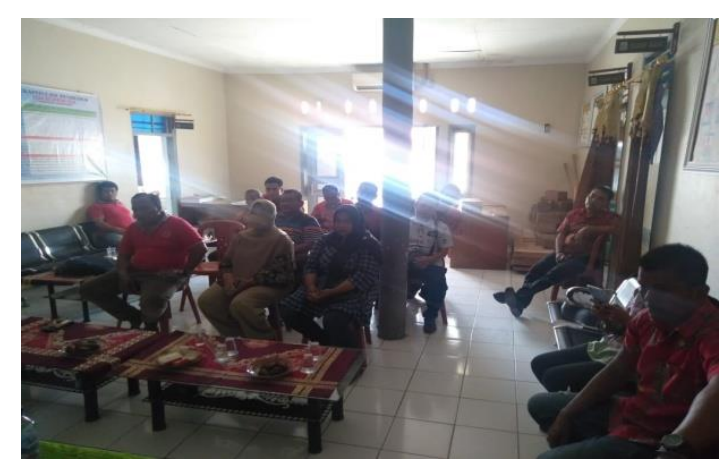

Gambar 2.

Sosialisasi dengan masyarakat

Pelaksanaan penanaman pohon dilaksanakan pada tanggal 16 dan 18 Februari 2020. Bibit tanaman yang ditanam adalah jenis tanaman buah-buahan. Adapun jenis tanaman dapat dilihat pada tabel berikut

Tabel 1

Jenis Tanaman

\begin{tabular}{ccc}
\hline No. & Jenis Tanaman & Jumlah \\
\hline 1 & Rambutan & 3 \\
\hline 2 & Mangga & 7 \\
\hline 3 & Kelengkeng & 8 \\
\hline 4 & Belimbing & 1 \\
\hline 5 & Petai & 2 \\
\hline
\end{tabular}

Kegiatan selama proses penanaman adalah :

1. Pemilihan bibit

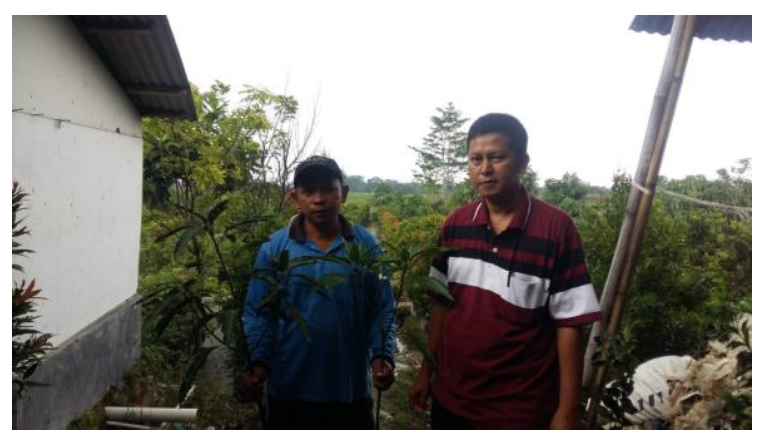

Gambar 3

Pemilihan Bibit 
2. Pembuatan lubang tanam

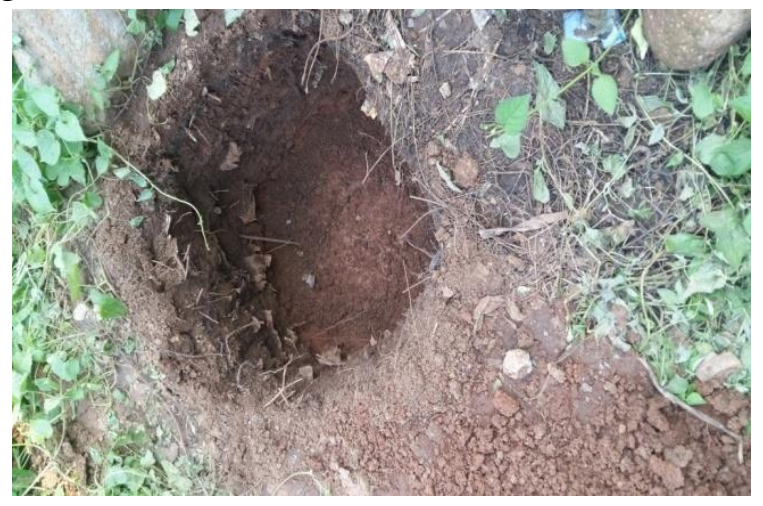

Gambar 4

Pembuatan Lubang Tanam

3. Penanaman Tanaman

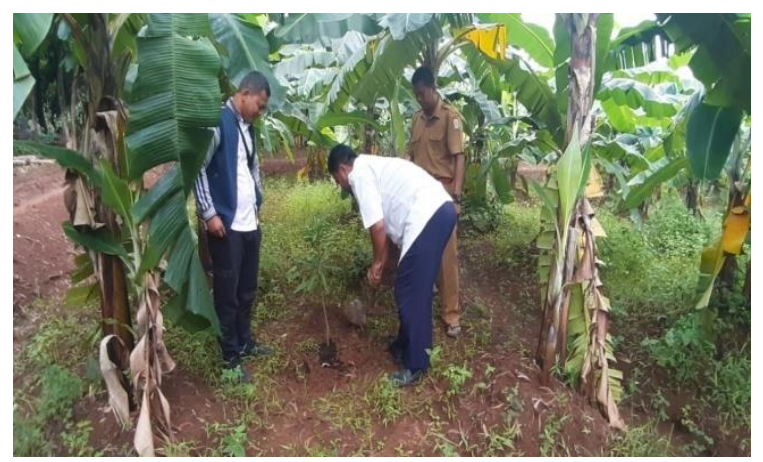

Gambar 6

Penanaman Tanaman

Kegiatan monitoring dilakukan 5 hari setelah dilakukan penanaman pohon. Adapun indikator hasil monitoring dan Evaluasi adalah :

1) Keberhasilan : Berhasil

2) Indikator Keberhasilan :

- Sosialisasi dilaksanakan dengan baik

- Masyarakat dan stakeholders mengikuti dan merespon kegiatan serta pemahaman materi tentang penghijauan daerah resapan

- Tanaman hidup dan tumbuh di lokasi penanaman

\section{Kesimpulan}

1. Dari kegiatan sosialisasi, seluruh stakeholder merespon kegiatan pengabdian masyarakat ini tentang penanaman pohon untuk daerah resapan

2. Pelaksanaan penanaman pohon dilaksanakan sesuai dengan jadwal serta masyarakat ikut berperan aktif dalam kegiatan penanaman pohon

3. Jenis tanaman yang ditanam adalah tanaman buah-buahan

4. Monitoring dan Evaluasi dilaksanakan setelah lima hari dari penanaman dan selanjutnya tanaman dipelihara oleh masyarakat sekitar 


\section{BIBLIOGRAFI}

Atmojo, Y. K., Irwan, S. N. R., \& Rogomulyo, R. (n.d.). Pemilihan Alternatif Pohon Buah Untuk Penghijauan Berdasar Karakteristik Tanaman Dan Kesesuaian Lahan Di Area Perkantoran Pemda Bantul, Manding, Yogyakarta. Vegetalika, 7(4), 7488.

Kutarga, Z. W., Nasution, Z., \& Tarigan, R. (2008). Kebijakan Pengelolaan Danau dan Waduk Ditinjau dari Aspek Tata Ruang.

Muslih, M. (2016). Pengaruh Lingkungan Keluarga Dan Lingkungan Sekolah Terhadap Prestasi Belajar Siswa Kelas 6 SDN Limbangan. Syntax Literate; Jurnal Ilmiah Indonesia, 1(4), 41-50.

Notohadiprawiro, T., Soekodarmodjo, S., \& Sukana, E. (2006). Pengelolaan kesuburan tanah dan peningkatan efisiensi pemupukan. Ilmu Tanah Fakultas Pertanian, Universitas Gajah Mada.

Sebastian, L. (2008). Pendekatan pencegahan dan penanggulangan banjir.

Semu, Y. D., Arsyad, U., \& Umar, A. (2018). Indikator Kinerja dan Peran Stakeholder dalam Pengelolaan Daerah Aliran Sungai (DAS) Lisu. Jurnal Hutan Dan Masyarakat, 10(2), 257-267.

Suryani, M. A. I., Arifin, Z., \& Hatta, H. R. (2017). Pemilihan Paket Wisata Menggunakan Metode Analytical Hierarchy Process (AHP). 